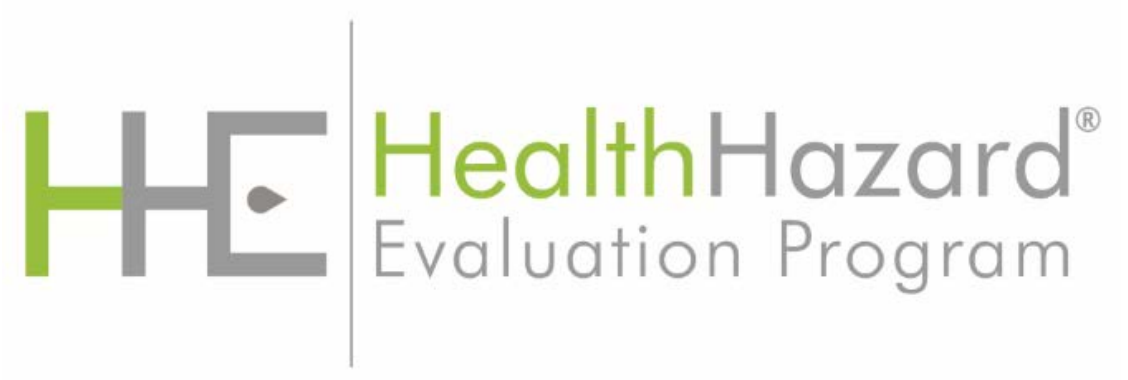

\title{
Evaluation of Rhabdomyolysis and Heat Stroke in Structural Firefighter $\mathrm{C}$ a dets
}

HHE Report No. 2018-0154-3361

November 2019

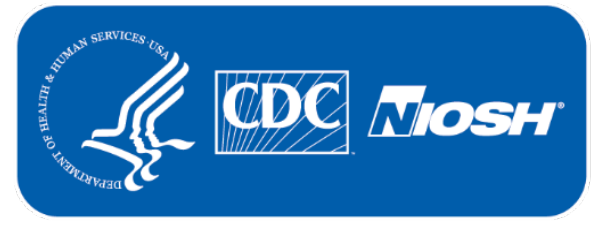


Authors: Judith Eisenberg, MD, MS

\section{Jessica F. Li, MSPH}

\section{Karl D. Feldmann, MS, CIH}

Desktop Publisher: Jennifer Tyrawski

Editor: Cheryl Hamilton

Logistics: Donnie Booher, Kevin Moore

Medical Field Assistance: Nonita Dhirar

Data Support: Hannah Echt

Keywords: North American Industry Classification System (NAICS) 922160 (Fire Protection), Structural Firefighter Training, Structural Firefighter Cadet Course, Heat, Heat-Related Illness, Heat Stroke, Rhabdomyolysis, Texas

\section{Disclaimer}

The Health Hazard Evaluation Program investigates possible health hazards in the workplace under the authority of the Occupational Safety and Health Act of 1970 [29 USC 669a(6)]. The Health Hazard Evaluation Program also provides, upon request, technical assistance to federal, state, and local agencies to investigate occupational health hazards and to prevent occupational disease or injury. Regulations guiding the Program can be found in Title 42, Code of Federal Regulations, Part 85; Requests for Health Hazard Evaluations [42 CFR Part 85].

\section{Availability of Report}

Copies of this report have been sent to the employer, employees, and union at the plant. The state and local health departments and the Occupational Safety and Health Administration Regional Office have also received a copy. This report is not copyrighted and may be freely reproduced.

\section{Recommended Citation}

NIOSH [2019]. Evaluation of rhabdomyolysis and heat stroke in structural firefighter cadets. By Eisenberg J, Li JF, Feldmann KD. Cincinnati, OH: U.S. Department of Health and Human Services, Centers for Disease Control and Prevention, National Institute for Occupational Safety and Health, Health Hazard Evaluation Report 2018-0154-3361, https://www.cdc.gov/niosh/hhe/reports/pdfs/2018-0154-3361.pdf. 


\section{Main Report}

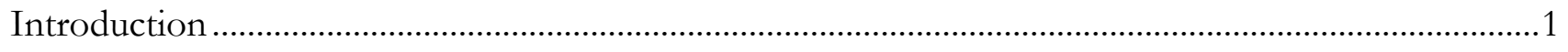

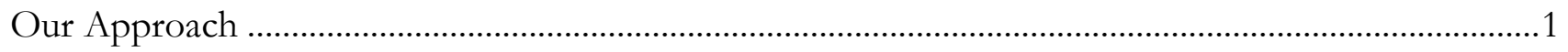

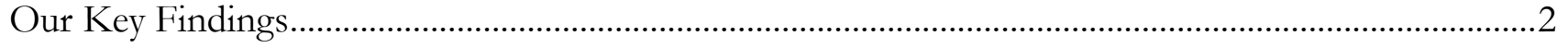

Our Recommendations ............................................................................................................

\section{Supporting Technical Information}

Section A: Background Information ........................................................................................ A-1

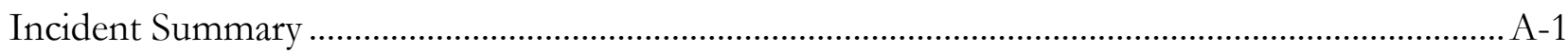

Training Facility and Course Information ..............................................................................

Section B: Methods, Results, and Discussion ……………………………………………….... B-1

Methods: Review of the Incident From June 2018 …………………………………............. B-1

Results: Review of the Incident From June 2018 .................................................................. B-2

Methods: Additional Document Review …………………………………………………….... B-3

Results: Additional Document Review ……………………………………………………. B-3

Methods: Environmental Conditions During Site Visit ............................................................. B-5

Results: Environmental Conditions During Site Visit .............................................................. B-5

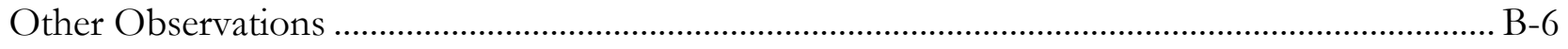

Methods: Knowledge Assessment …………………………………………………….... B-7

Results: Knowledge Assessment....................................................................................... B-7

Methods: Cadet Admissions Process Review............................................................................ B-8

Results: Cadet Admissions Process Review ……………….......................................................... B-8

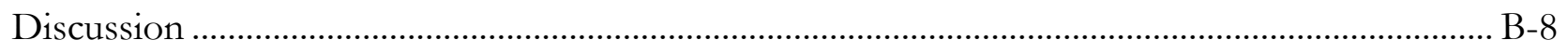

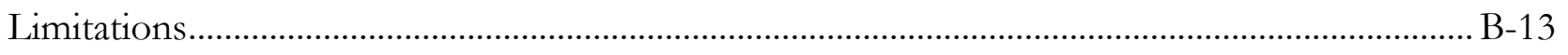

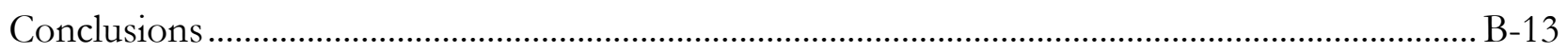

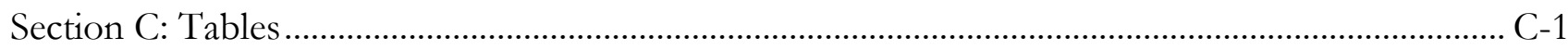

Section D: Occupational Exposure Limits .......................................................................................

Heat Stress ................................................................................................................... D-2

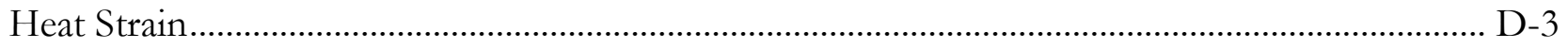

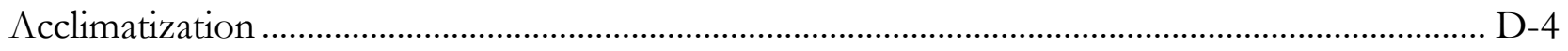

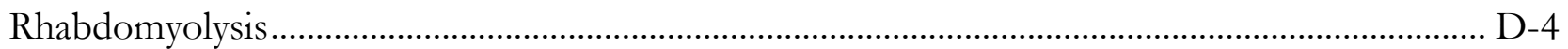

Section E: Heat Stroke and Rhabdomyolysis Knowledge Assessment................................................ E-1

Section F: References........................................................................................................ F-1 
This page left intentionally blank 


\section{Introduction}

\section{Request}

A representative of a city-operated structural firefighter cadet training program requested a health hazard evaluation concerning heat-related (HRI) illness and rhabdomyolysis among cadets. The request was prompted by the death of one cadet and the hospitalization of another in the same class for heat stroke and rhabdomyolysis. Both cadets became ill on the first day of the training course.

\section{Workplace}

Cadet training consisted of the following components:

- Indoor classroom lectures

- Indoor and outdoor physical fitness activities (e.g., weight training, group and individual running, group and individual exercises)

- Outdoor firefighter task-based exercises (e.g., using firefighting tools, victim rescue, live-fire suppression)

At the time of our evaluation, the cadet course was six months long, and class sizes ranged from 30 to 80 cadets. Classes trained cadets 8 to 10 hours a day, 5 days a week. The facility conducted classes year-round and may train two classes concurrently.

All cadets were required to pass the state-administered emergency medical technician and certified firefighter exam before graduating from the academy. The city-operated firefighter training facility was co-located with the police training facility on a multibuilding, multiacre site. Firefighter training facilities (e.g., weight room, fire tower, etc.) were open and available after hours for cadet and all training facility staff to use.

To learn more about the workplace, go to Section A in the Supporting Technical Information

\section{Our Approach}

We visited the firefighter cadet training facility for two days in August 2018, which were Days 36 and 37 of the 126th cadet training course. During this site visit, we completed the following activities:

- Met with training course management, instructors, and support staff, including the medical director, exercise physiologists, and the workers' compensation claims manager.

- Reviewed written facility policies, incident reports, workers' compensation claims, and medical records.

- Observed cadet outdoor physical fitness activities and firefighter task-based training exercises. 
- Recorded environmental conditions and estimated metabolic effort expended during outside activates and exercises.

- Administered a knowledge assessment on HRI and rhabdomyolysis to all Class 126 cadets and instructors present on the second day of the site visit.

To learn more about our methods, go to Section B in the Supporting Technical Information

\section{Our Key Findings}

Cadets and instructors were at increased risk for rhabdomyolysis and heat-related illness

- Firefighting exercises and physical fitness training regimens often involve activities which can increase risk for rhabdomyolysis and HRI.

- Instructors often participated in cadet exercises as safety officers and to encourage cadet efforts.

- A knowledge assessment completed by cadets and instructors identified that additional training is needed on both conditions to increase early recognition and reduce modifiable risk factors.

The facility's heat stress management program could be improved

- The heat stress management program lacked important components including:

o Guidelines on how to assess outdoor heat conditions.

o Clear actions to take based on the assessment of outdoor heat conditions, such as guidelines for postponing, shortening, or rescheduling outdoor training.

0 Required use of the buddy system when engaging in activities that may increase risk for HRI (i.e., outdoor calisthenics, indoor gym workouts, etc.).

- A knowledge assessment completed by cadets and instructors identified that additional training is needed on HRI and rhabdomyolysis.

The delay period between acceptance into the program and the start of training can put cadets at risk for rhabdomyolysis

- Cadets may experience a delay of up to 2 years between acceptance into the program and the start of their cadet training.

- Accepted cadets do not receive guidance on safe practices to maintain their physical fitness or heat acclimatization during the delay period.

- Cadets may engage in vigorous physical fitness training immediately before the start of the training course as a result of this delay. 
- Medical reassessments of cadets were not required before the start of the training course.

During this delay, cadets may develop medical conditions that could

o Disqualify the cadet from entering training according to National Fire Protection Association guidelines.

o Place the cadet at increased risk for HRI and rhabdomyolysis.

To learn more about our results, go to Section B in the Supporting Technical Information

\section{Our Recommendations}

The Occupational Safety and Health Act requires employers to provide a safe workplace.

Benefits of Improving Workplace Health and Safety:
个 Improved worker health and well-being
个 Enhanced image and reputation
个 Better workplace morale
个 Superior products, processes, and services
$\uparrow$ Easier employee recruiting and retention
$\uparrow$ May increase overall cost savings

The recommendations below are based on the findings of our evaluation. For each recommendation, we list a series of actions you can take to address the issue at your workplace. The actions at the beginning of each list are preferable to the ones listed later.

\section{Recommendation 1: Expand the facility's existing heat stress management program}

Why? A comprehensive heat stress management policy is crucial to the prevention of HRI and rhabdomyolysis in employees and others who engage in strenuous work in hot environments. Education and refresher training on HRI and rhabdomyolysis are important components of any heat stress management program.

How? At your workplace, we recommend these specific actions:

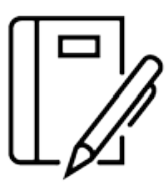

Incorporate heat stress prevention strategies from the National Institute for Occupational Safety and Health (NIOSH) Heat Stress Criteria document

A comprehensive heat stress management program for the training facility should include the following:

- Require all cadets and city employees who use the facility to have initial and periodic refresher training on HRI and rhabdomyolysis.

- Include procedures on how to assess environmental heat conditions. 
o Outline actions to take based on the assessment of the environmental heat conditions (e.g., discontinue outdoor training during specific conditions).

o Include a method for communicating environmental heat conditions to all facility staff and cadets (e.g., a modified flag system, text notification system).

- Require use of the buddy system for all personnel (cadets, instructors, and facility support staff) when using outdoor or indoor facilities.

- Encourage employees and cadets to rehydrate with low-sugar or sugar-free and caffeinefree drinks.

o Consider posting educational materials cited below in cadet and instructor break areas and near vending machines.

o Consider stocking vending machines solely with low-sugar or sugar-free and caffeine-free drinks.

More information about the components of a comprehensive heat stress management program can be found in the NIOSH Criteria for a Recommended Standard: Occupational Exposure to Heat and Hot Environments. Additionally, the following documents may be useful:

- Rhabdomyolysis fact sheet for structural firefighters: Rhabdomyolysis: What Structural Firefighters Need to Know.

- Fact sheet for structural firefighters' healthcare providers: Rhabdomyolysis in Structural Firefighters: A Patient Population at Risk.

- Wallet card describing the increased risk for rhabdomyolysis in structural firefighters. This card is for firefighters to present to healthcare providers when seeking care for possible rhabdomyolysis symptoms. It reminds the provider of the inherent risks for rhabdomyolysis in firefighters and recommends early check of serial creatine kinase measurements.

- See the NIOSH Health Hazard Evaluation report, Evaluation of Heat Stress, Heat Strain, and Rhabdomyolysis During Structural Fire Fighter Training, for additional recommendations for reducing the risk of HRI and rhabdomyolysis in structural firefighters.

\section{Reduce barriers to seeking prompt medical evaluation and treatment for possible HRI and rhabdomyolysis symptoms.}

- Establish a clear departmental return-to-work or training policy (for both cadets and instructors) following a healthcare provider evaluation for possible HRI and rhabdomyolysis symptoms. This policy should address obtaining a medical clearance for return-to-work after any type of illness or other medical issues. 
- Provide periodic refresher training on the department's workers' compensation system, which may also lower barriers to seeking prompt care due to financial concerns.

Recommendation 2: Utilize the department's exercise physiologists to help cadets safely maintain their physical fitness and heat acclimatization prior to the start of their training course

Why? There may be a delay of up to 2 years for some cadet applicants between the physical ability test and the start date of their cadet course. This delay may result in decreased physical fitness levels in some cadet applicants who may then engage in self-imposed intense physical training regimens immediately prior to the start of the training course. Engaging in high intensity physical fitness activities can increase the risk for rhabdomyolysis.

How? At your workplace, we recommend these specific actions:

Personalize physical fitness programs for each incoming cadet's baseline physical fitness level and their interim period.

- Base each cadet's program on their performance of the candidate's physical ability test taken during the application process and their anticipated training start date.

- Provide this personalized physical fitness program to each cadet on their acceptance into the training program.

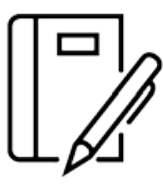

Include information on heat acclimatization with the individualized physical fitness program.

- Inform cadets that travel to a cooler climate in the 2 weeks before the start of their training may place them at increased risk of HRI due to the loss of their heat acclimatization.

Recommendation 3: Consider implementing a medical reassessment policy if more than a 3-6 month delay occurs between a cadet's initial medical evaluation and the start of their assigned training course

Why? Changes in an incoming cadet's medical status may place them at increased risk for injury or illness during the training course. Implementing a medical reassessment program will help ensure cadets are still in good health to undergo this training safely. 
How? At your workplace, we recommend these specific actions:

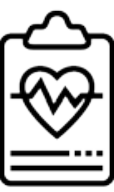

\section{Require a health status update from cadets one month before their} training course start date.

This will allow the department's medical staff to

- Document health status just prior to starting training.

- Determine if any additional medical evaluation is needed for the cadet to safely start this rigorous training course.

- Complete any additional medical assessments that may be indicated for new medical issues or worsening of preexisting medical conditions before the training start date. 


\section{Supporting Technic al Information}

Evaluation of Rhabdomyolysis and Heat Stroke in Struc tural Firefighter Cadets

HHE Report No. 2018-0154-3361

November 2019 


\section{Section A: Background Information}

\section{Incident Summary}

In June 2018, on the first day of a firefighter cadet training course, two previously healthy cadets were transported to the local emergency department (ED) within 90 minutes of the start of the class. Cadet A collapsed 16 minutes after beginning a stair climbing exercise and died the next day. Cadet B collapsed about 1 hour after Cadet A. Cadet B was discharged from the hospital after 5 days and resumed training with the next class. Both cadets were reported to have diagnoses of HRI and rhabdomyolysis.

\section{Training Facility and Course Information}

The cadet training facility trained firefighters for a 45-station metropolitan fire department serving an area of 272 square miles and a population of almost one million. The firefighter training facility included classrooms, an indoor gym, an outdoor track, a fire tower, and structures for firefighting exercises.

At the time of our evaluation, the cadet training course was 28 weeks long. Cadets trained eight to ten hours a day, five days a week. The facility conducted classes year-round and may train two classes concurrently. Annual cadet intake numbers changed from year to year depending on staffing needs and available budget. In 2018, the facility completed training for 116 cadets. This department may certify 400 eligible applicants per intake season, but it may take up to 2 years to place these applicants in a specific cadet training class. 


\section{Section B: Methods, Results, and Discussion}

Our evaluation had the following objectives:

- Determine the effectiveness of the department's written heat stress management policy and HRI and rhabdomyolysis training materials.

- Review the frequency of HRI and rhabdomyolysis reports in cadets and instructors over the past five years.

- Determine any training program policies that could be amended to lower potential barriers to reporting and seeking care for possible HRI and rhabdomyolysis symptoms in both cadets and instructors.

- Consider possible improvements to the cadet application and admission process that could reduce the risk of HRI and/or rhabdomyolysis in incoming cadets.

To achieve these objectives, we used these methods:

1. Reviewed the facility's written Heat Stress Management Policy and other relevant documents.

2. Measured wet-bulb globe temperature (WBGT) and estimated metabolic workload during outdoor cadet training exercises. The WBGT value includes heat from factors such as humidity, radiant heat, solar load, and wind speed.

3. Conducted an HRI and rhabdomyolysis knowledge assessment of current cadets and instructors.

4. Reviewed the cadet admission process and assessed its impact on incoming cadets' risk of HRI and rhabdomyolysis.

Investigating the death of Cadet A was outside the scope of this evaluation - summary information related to Cadet A is provided in this report. A detailed analysis of the cadet's death and targeted prevention strategies will be covered in the NIOSH Fire Fighter Fatality Investigation and Prevention Program (FFFIPP) report of this case (F2018-15). More information on the NIOSH FFFIPP can be found at https://www.cdc.gov/niosh/fire/default.html.

\section{Methods: Review of the Incident From June 2018}

Information that contributed to our review of the June 2018 incident included these sources:

- Interviews of training center staff present at the time of the incidents.

- Review of records associated with the incident including the department's incident reports, ambulance trip sheets, ED records, inpatient medical records, and the autopsy report.

- Review of the training program application materials of both cadets.

- Review of historical weather data to assess ambient heat conditions on the day and time of both cadets' incapacitations. 


\section{Results: Review of the Incident From June 2018}

In June 2018, on the first day of the training course, two cadets required emergency transport from the training facility. The training day started at 7:00 a.m. with cadets immediately commencing a stair climb exercise. Based on information from external weather sources, the WBGT during the time of the incident was calculated between $82^{\circ} \mathrm{F}$ and $84^{\circ} \mathrm{F}$.

Cadet A, a 34-year-old male with no known medical problems, collapsed at 7:16 a.m. while climbing stairs carrying a hose bundle. On arrival to the local ED, this cadet was noted to be in respiratory and renal failure with a blood clot in his leg. He was found to be in rhabdomyolysis and possibly heat stroke. As per emergency medical service records, his initial rectal temperature was $102.9^{\circ} \mathrm{F}$. This cadet died the followed evening. The autopsy report determined the cause of death to be atherosclerotic and hypertensive cardiovascular disease with hyperthermia (elevated core body temperature) noted as a contributing factor.

Cadet B, a 29-year-old male with no known medical problems, became lightheaded, nauseated, and dizzy. He stated that he felt like he was going to pass out after climbing nine flights of stairs twice around 8:00 a.m. This cadet denied having any chest pain, muscle pain or cramping, or any recent change in urine color. The responding ambulance crew noted that his heart rate and breathing rate were elevated, and he appeared sweaty. Cadet B reported having a similar episode about 1 year ago but was not medically evaluated.

On arrival to the ED, Cadet B reported an acute onset of muscle pain and cramping, and his vital signs showed an elevated heart rate but normal breathing rate and body temperature. Initial physical examination was remarkable for dehydration with dry mucus membranes, but no extremity tenderness or asymmetric swelling was noted. The initial serum creatine kinase (CK) level, the blood test for rhabdomyolysis, was 12,569 units per liter $(\mathrm{U} / \mathrm{L})$. The hospital laboratory's reference range for this test was 39-308 U/L, indicating evidence of rhabdomyolysis.

Cadet B was admitted to the hospital with diagnoses of severe acute exertional rhabdomyolysis, acute renal failure, and electrolyte abnormalities. Aggressive treatment with intravenous fluids was initiated and kidney function fully recovered. Serum CK level peaked at 86,517 U/L and decreased to 4,781 U/L just prior to discharge 5 days later. The hospital discharge instructions advised Cadet B to avoid strenuous physical activities, extreme hot and/or humid environments, and heavy lifting but did not state when these restrictions could be lifted. Cadet B was medically cleared by his primary care provider to return to cadet training. As an added precaution, Cadet B waited until the start of the next class (October 2018) to resume training.

As per department records, both Cadets A and B began the application process in January 2018. The department's medical director signed off on their physical examinations in March 2018 for Cadet A and in February 2018 for Cadet B.

The weather conditions were not specified in the emergency medical services or ED records. We searched historical weather data for environmental conditions at the cadet training center on the day of the incident in June 2018. We found historical weather data through the National Oceanic and Atmospheric Administration's (NOAA) National Centers for Environmental Information and the 
Weather Underground website. We used both sources of meteorological information because the Weather Underground website provided hourly temperatures in their archived data while NOAA's historical database provided daily summary temperature measurements. Hourly temperature measurements were needed to assess the ambient conditions at the time the cadets became ill. We calculated the heat index and WBGT using this data. The heat index is a measure of how hot it feels when relative humidity is considered with the air temperature.

NOAA data for the day of the incident in June 2018 stated that the maximum air temperature recorded was $95^{\circ} \mathrm{F}$, the minimum air temperature recorded was $77^{\circ} \mathrm{F}$, and the average air temperature was $85^{\circ} \mathrm{F}$. This data also did not include relative humidity measurements.

Weather Underground data included hourly air temperature, dew point and relative humidity, wind speed and direction, and cloud cover conditions. These values are in Table C2 in Section C. The heat index during the time of the incident was between $96^{\circ} \mathrm{F}-101^{\circ} \mathrm{F}$. Based on this information, we calculated the WBGT during the time of the incident to be between $82^{\circ} \mathrm{F}$ and $84^{\circ} \mathrm{F}$.

\section{Methods: Additional Document Review}

We reviewed the following firefighter cadet training facility documents:

- Heat stress management policy dated September 1, 2014.

- Hydration guidelines (undated).

- Cadet fitness manual (undated).

- Injury and illness incident reports for cadets and incumbent firefighters for January 1, 2013August 15, 2018.

- Workers' compensation claims for January 1, 2013-August 15, 2018.

\section{Results: Additional Document Review}

\section{Heat Stress Documents}

The heat stress management policy was a two-page document and contained only the following three elements:

- Recommendation for hydration fluid intake at a constant rate of 8-12 ounces every 15-20 minutes.

- Generic information on HRI.

- Guidelines on using a fan primarily used to disperse smoke (i.e., smokebuster) to help cool down firefighters.

The heat stress management policy was missing the following guidelines:

- Method for obtaining environmental heat stress data (either by training staff to use a wet bulb globe thermometer or listing vetted sources of environmental heat stress data) and how the data could be used. 
- Evaluation of tasks to estimate metabolic heat load to determine if the total heat exposure exceeds the applicable NIOSH recommended alert limit (RAL) or recommended exposure limit (REL) [NIOSH 2016].

- Detailed HRI and rhabdomyolysis training for cadets and instructors.

- Requirement to use the buddy system when HRI could occur, such as outdoor training during hot weather or use of indoor training facilities when metabolic effort alone could result in HRI.

- Cadet maintenance of heat acclimatization prior to the beginning of the training course.

- Air-conditioned cooling stations or misting fans usage.

- Medical monitoring program with these specific recommendations:

o Preplacement medical evaluation focusing on risk factors for HRI and screening for any disqualifying medical conditions.

o Periodic medical evaluations, at least annually, to include screening for HRI and rhabdomyolysis risk factors.

o Voluntary method for exchanging information with the cadet's personal healthcare provider.

o Encouragement to seek prompt medical care if cadets develop signs or symptoms of HRI or rhabdomyolysis.

o Review process for past incidents of HRI and rhabdomyolysis in both cadets and incumbents.

\section{Facility Injury and IIIness Records via Workers' Compensation Claims Reports}

Eleven cadet classes (Classes 116-126) were held at this training center from January 1, 2013, to January 4, 2019, with two classes running concurrently on only one occasion. The concurrent classes were Classes 123 and 124, which started on November 13, 2017. There were no reports of HRI or rhabdomyolysis from either of these classes. Class 122, which started on July 24, 2017, was the only other class during our review period that did not have any cadet injury reports of HRI or rhabdomyolysis.

Of the remaining eight classes, 16 cadets reported 19 separate incidents of heat exhaustion and/or rhabdomyolysis. Of these 16 cadets, 15 (94\%) were male, and their median age was 33 years (range: 26-38 years). All were sent to the hospital, and four were hospitalized (this included the two cadets involved in the June 2018 incident). Of the 19 illness reports, 10 (53\%) reported rhabdomyolysis as the entire or partial diagnosis, and heat exhaustion was reported in whole or in part in 12 of the 19 reports. The 19 illness reports included diagnoses as follows: four "rhabdo/dehydration," four "heat exhaustion/dehydration," three rhabdomyolysis alone, five heat exhaustion alone, and three "rhabdomyolysis/heat exhaustion." Out of the total 16 affected cadets, only 6 (38\%) completed training; all did so after rejoining their original class. Only one of these four who completed their training required inpatient care for their illness. Cadet B resumed training with class 127 but did not complete the course. 
The 19 incidents occurred throughout the calendar year with the highest number of total cases (12) occurring during the summer months (six in June, four in July, and two in August). During the fall, six incidents were reported (none in September, five in October, and one in November) followed by one report in the spring (March), and none in the winter. During the same period of review, incumbent firefighters submitted only three claims for HRI and/or rhabdomyolysis. This fire department currently employs approximately 1,200 firefighters.

Of the 19 incidents, the median onset of illness occurred 74 days into the course (range: 0-141 days). Aside from the June 2018 incident, only one other incident was reported in the past 5 years of a cadet becoming ill with HRI and/or rhabdomyolysis on the first day of training; this occurred in March 2018. As with the two cases in June 2018, the report noted that this cadet became ill while engaged in physical training. This cadet survived but did not complete training. It is not known from the report how long the cadet had been engaged in physical training that day before becoming ill. No cadets with more than one report of heat exhaustion and/or rhabdomyolysis during the review period completed the training course.

The injury reports detailed the activity the cadets were doing at the time of illness onset. All 16 cadets became ill while engaging in some form of physical activity either as part of the physical training program or during firefighter-specific training exercises. Because of the lack of uniform reporting methods, there were overlapping activity descriptions. Six (35\%) reports mentioned "physical training" or "PT" in their description while other reports noted the specific exercise cadets were doing as part of the physical training session (e.g., burpees, running laps). The fire tower was specifically mentioned in six reports of activity at illness onset.

\section{Methods: Environmental Conditions During Site Visit}

We used a Quest Technologies QUESTemp 36 instrument to measure WBGT. The WBGT measurements were data-logged at 1-minute intervals for the entire day and manually recorded on a daily activity log for each task. The daily activity log was also used to describe each work task, its duration, and its estimated metabolic load (exertion level) using the NIOSH and American Conference of Governmental Industrial Hygienists (ACGIH) heat stress guidelines [ACGIH 2019; NIOSH 2016]. Exertion levels were classified as light (180 watts [W]), moderate (300 W), heavy (415 W), and very heavy $(520 \mathrm{~W})$. When employees did not wear cotton uniforms, a clothing adjustment was applied to the WBGT [ACGIH 2019].

\section{Results: Environmental Conditions During Site Visit}

On the first day of our visit, cadets were tested on individual fire skills. Fire skills are proficiencies required while fighting a fire (e.g., navigating a building interior with poor or no visibility; searching for, securing, and removing victims, etc.). Cadets were able to complete and move between fire skill stations at their own pace, and they were allowed time to rest in the shade, hydrate, and take off their protective clothing. Cadets worked on fire skills individually or in groups of two or more, depending on the specific exercise. Because cadets moved freely and performed these skills individually, we were unable to observe the performance of all the fire skills for all cadets. 
We collected WBGT measurements ranging $82^{\circ} \mathrm{F}-92^{\circ} \mathrm{F}$ during the morning fire skills training session. All the skills on this day required donning of full protective clothing for structural firefighters (consisting of helmet, gloves, coat, trousers, boots, hood, and self-contained breathing apparatus [SCBA]). Some skills required donning SCBA facepieces and breathing SCBA air. A WBGT clothing adjustment was not made because the short amount of time each participant wore this protective equipment (maximum task lengths were six minutes). Estimated metabolic rate categories for the fire skills ranged from light $(180 \mathrm{~W})$ to very heavy $(520 \mathrm{~W})$, and the duration for most activities was under two minutes. Two fire skills took four to six minutes with estimated metabolic rate category of moderate $(300 \mathrm{~W})$.

Environmental heat stress conditions could have exceeded the REL if cadets conducted fire skill activities throughout the duration of the allotted time. For example, at a WBGT of $91.4^{\circ} \mathrm{F}$, all activities above a resting exertion level (light, moderate, heavy, or very heavy) would exceed the REL if performed continuously for 1 hour (Figure B1). Because of the short duration of each fire skill, it is not likely that the REL was exceeded. We observed cadets taking rest breaks in the shade and drinking water at their own discretion.

On the second day of the visit, one class of cadets had 1 hour of physical training consisting of activities with estimated metabolic rate categories of moderate $(300 \mathrm{~W})$ to heavy $(415 \mathrm{~W})$. Physical training began at 7:00 a.m. WBGT measurements were $82^{\circ} \mathrm{F}-85^{\circ} \mathrm{F}$ during these activities. Cadets were wearing cotton shirts, cargo pants, and baseball caps. The cadets spent the remainder of the day in the classroom. Environmental conditions exceeded the REL during physical training.

\section{Other Observations}

Informal discussion with training center staff disclosed an unofficial, unwritten policy allowing instructors to start the training day 1 hour earlier because of anticipated heat conditions. The first hour of the cadet training day was usually composed of outdoor exercises. At the time of our evaluation, there were no set criteria for making this shift in start time.

Discussions with staff and exercise physiologists reported that it was common for cadets, especially those with long delays between their application and acceptance and their actual training start date, to engage in a self-imposed "boot camp" (referring to short duration high intensity physical fitness training programs) in the days just prior to the start of their training course. Although these exercise physiologists are instrumental in the design and implementation of cadet physical fitness programs, they do not have contact with the cadets until they start their assigned cadet class. Cadets who have been accepted into the training program but not assigned to a specific class do not get any guidance from these exercise physiologists regarding safe training practices during this interim period. There was also no formal discussion with accepted cadets regarding heat acclimatization that could place them at increased risk for HRI if they travel to a cooler climate just preceding their training start date.

Informal discussions with staff also revealed that any employee of the training facility or incumbent firefighters could use the department's facility alone during off-hours. The cadet training program relies heavily on incumbent firefighters from fire stations across the department's coverage area to teach specific subjects during the cadet training course. This results in the facility hosting several "guest" 
instructor firefighters at any time who may use these training areas for their own workouts. Some of these training areas (such as the fire tower and indoor gym) were in remote locations without access control (e.g., ID card reader to access the training area), an emergency alarm, or closed-circuit video coverage that could alert facility security to a medical emergency.

\section{Methods: Knowledge Assessment}

To determine the effectiveness of current HRI training materials and the level of knowledge of rhabdomyolysis, all 48 cadets and instructors present in the cadet classroom on the second day of our site visit, were invited to complete a short knowledge assessment quiz. We provided 20 minutes to complete the 10-question knowledge assessment. The knowledge assessment along with the correct answers are provided in Section E.

\section{Results: Knowledge Assessment}

In total, 47 of 48 individuals present participated in completing the knowledge assessment, resulting in a 98\% participation rate. Of the 47 completed knowledge assessments, 7 (15\%) were completed by instructors, and 40 (85\%) were completed by cadets. The seven instructors had a median age of 36 years (range: 31-47 years), and all had prior structural and/or wildland firefighting experience. The 40 cadets had a median age of 29 years (range: $21-37$ years), and 45\% reported prior structural and/or wildland firefighting experience.

Details of the knowledge assessment results are in Table C1. Two questions that tested participants' knowledge about heat stroke had mixed results. Cadets and instructors had similar performance with $14 \%$ of instructors and 15\% of cadets correctly identifying all four statements concerning heat stroke as true or false. Most participants correctly identified three out of the four statements: It is true that "Heat stroke can be fatal if not recognized and treated quickly." It is false that "The buddy system does not help in early recognition of heat stroke" and "The core body temperature has to be above $102^{\circ} \mathrm{F}$ to be heat stroke." Correct response rates for these three statements were between 85\%-100\% for both participant groups. However, only $29 \%$ of instructors and $30 \%$ of cadets correctly labeled the statement "Heat stroke is a change in mental status while in a hot environment" as true. Most participants did well in identifying work practices used to reduce risk of heat stroke, with correct responses for all listed work practices given by $100 \%$ of the instructors and $75 \%$ of the cadets.

All participants were able to correctly identify five general statements about rhabdomyolysis as true or false. However, none of the instructors and only one cadet $(3 \%)$ correctly identified all the signs (parameters that can be objectively measured) and symptoms (subjective experiences reported by someone with the condition) associated with rhabdomyolysis. All participants correctly identified muscle pain and kidney failure as being associated with rhabdomyolysis. Between $78 \%-100 \%$ of participants correctly identified exercise intolerance, tea- or cola-colored urine, cardiac arrhythmias, seizures, and permanent disability as signs and symptoms associated with rhabdomyolysis. None of the instructors and only five (13\%) cadets incorrectly identified pain on urination as associated with rhabdomyolysis. In total, $57 \%$ of instructors and $40 \%$ of cadets correctly identified CK as the correct lab test for rhabdomyolysis. 
The question asking participants to list all risk factors for rhabdomyolysis revealed additional knowledge gaps. The three most commonly correctly identified risk factors for rhabdomyolysis were overexertion, use of stimulants, and hyperthermia, with respective overall response rates of $68 \%, 49 \%$, and $45 \%$. Lack of heat acclimatization (three mentions; $6 \%$ overall) and alcohol (one mention; $2 \%$ overall) were the least mentioned correct risk factors.

Most (55\%) participants identified this department's training materials as their most frequently used source of information on heat stroke and rhabdomyolysis followed by online resources such as WebMD (40\%) and coworkers and friends (30\%). Only three participants (two cadets and one instructor) reporting getting information on these subjects from their healthcare provider.

\section{Methods: Cadet Admissions Process Review}

Information regarding the cadet admissions process was obtained through discussions with department leadership and on the department's website guide for potential applicants.

\section{Results: Cadet Admissions Process Review}

At the time of our evaluation, cadet applicants who passed initial background screenings were "invited" to complete a Candidate Physical Ability Test (CPAT). The CPAT is an assessment of the candidate's flexibility, aerobic and anaerobic capacity, muscle strength, and "muscle endurance." The CPAT consists of eight separate events and is graded in a pass/fail manner. A CPAT training preparation guide produced by the department suggested activities applicants can do to prepare for the CPAT, including various exercises meant to simulate tasks they will need to perform as a structural firefighter. In addition to the CPAT, candidates were also required to take and pass a treadmill test. Both the CPAT and treadmill tests had to be conducted at the training facility.

This department had three full-time exercise physiologists who were part of the department's Wellness Center headed by the medical director (Wellness Director). The exercise physiologists' main role was to assist in the development of the physical fitness program component of the cadet training course. They also produced the department's fitness manual. This manual included a half page section on Heat Illness Prevention. The exercise physiologists did not interact with the cadets prior to the start of their assigned training course.

Cadet applicants were also required to submit comprehensive medical history reports that were reviewed by the Wellness Director to determine if they had any disqualifying conditions as per the National Fire Protection Association (NFPA) Standard 1582 [NFPA 2018]. In cases where cadet applicants were former employees of the fire department or training facility administrative staff, an alternative provider not associated with this department performed the medical clearance assessments to avoid bias. Accepted candidates were notified of their assigned class number and the start date for their training course. As per the training center director, accepted cadets may wait up to two years to start their cadet training.

\section{Discussion}

This firefighter cadet training program experienced two cases of HRI and rhabdomyolysis among cadets in June 2018. It has long been recognized that "firefighting activities are strenuous and often require 
firefighters to work at near maximal heart rates for long periods" [Fahy 2005]. One of the first reports of rhabdomyolysis in cadet firefighters occurred in 1988 in the New York City Fire Department following a physical fitness test simulating firefighter tasks lasting a maximum of 7 minutes while wearing nearly 40 pounds of gear. In the 19-month study period, one cadet died, 32 were hospitalized, and 41 were treated and released from EDs for "rhabdomyolysis and/or acute renal failure" [Centers for Disease Control and Prevention 1990].

The contribution of exertion to heat stroke is often underappreciated. Exertional heat stroke can and does occur at ambient temperatures that may not seem excessive. The contribution of metabolic heat generated through physical exertion to the development of heat stroke was illustrated by a previous firefighter fatality at a different department that NIOSH investigated in 2018. In that case, a structural firefighter cadet died of hyperthermia and dehydration while engaged in a smoke maze exercise. Although the cadet wore full turnout gear, no live fire was involved in this exercise. The cadet became incapacitated after 30 minutes at which time the ambient temperature was $75^{\circ} \mathrm{F}$ with a relative humidity of $96 \%$, resulting in a heat index of $77^{\circ} \mathrm{F}$. The cadet's rectal temperature was $108.2^{\circ} \mathrm{F}$. Despite active cooling measures, the cadet was pronounced dead about 1 hour later. The cause of death was listed as "hyperthermia and dehydration" [NIOSH 2018].

The heat contribution from exertion should be approached as a health hazard just as serious as potential heat exposure occurring outdoors during excessive ambient heat conditions. It is concerning that some of the fitness facilities at this training center where exertional heat stroke may occur were located in remote areas of the facility without access control, visibility on a closed-circuit video monitoring system, or medical emergency call alarms. The lack of these safety features could result in a poor outcome if a staff member working out alone needed assistance for heat stroke or other medical emergencies.

Ensuring that firefighters are in optimal physical condition is an important risk reduction strategy, starting from the time they begin cadet training and throughout their careers as incumbent firefighters. The NFPA recognized this and set the standard for medical assessment of new firefighters and ongoing fitness for duty programs for career firefighters [NFPA 2018]. However, maintaining this effort has proved challenging for the fire service. Evaluation of 189 firefighter fatality investigations conducted by NIOSH's FFFIPP during 2004-2009 found that the "need for greater attention to preplacement and annual fitness for duty evaluations" was still one of the most frequently issued recommendations [Kunadharaju et al. 2011].

It cannot be determined if a change in either cadet's health status had occurred during the 6 months between the start of their application process and their first day of training in June 2018. However, the risk for such an occurrence may increase as that interim period lengthens. A reassessment of cadet candidates' medical conditions just prior to starting training could ascertain if incoming cadets have developed conditions that would place them at increased risk of HRI and rhabdomyolysis during cadet training. Guidance from the department's exercise physiologists upon program acceptance may help these incoming cadets avoid risky physical fitness and conditioning programs and reinforce the importance of maintaining heat acclimatization leading up to the start of their cadet training course.

Our review of cadet injury reports during training revealed 19 reported cases of rhabdomyolysis and/or HRI over a five-and-a-half-year period. Our environmental assessment identified metabolic rates 
ranging from light to very heavy. In addition, on the day of the incident in June 2018, we estimated that the WBGT was between $80^{\circ} \mathrm{F}$ and $84^{\circ} \mathrm{F}$ using historical weather data. At these temperatures, an unacclimatized person would exceed the RAL if they were performing heavy work 30 minutes per hour. An acclimatized person would exceed the REL if they were performing heavy work for longer than 45 minutes per hour (Figure B1). Exceeding the RAL or REL increases the risk of HRI and rhabdomyolysis as these environmental conditions make it harder for the body to thermoregulate, leading to rises in the core body temperature.

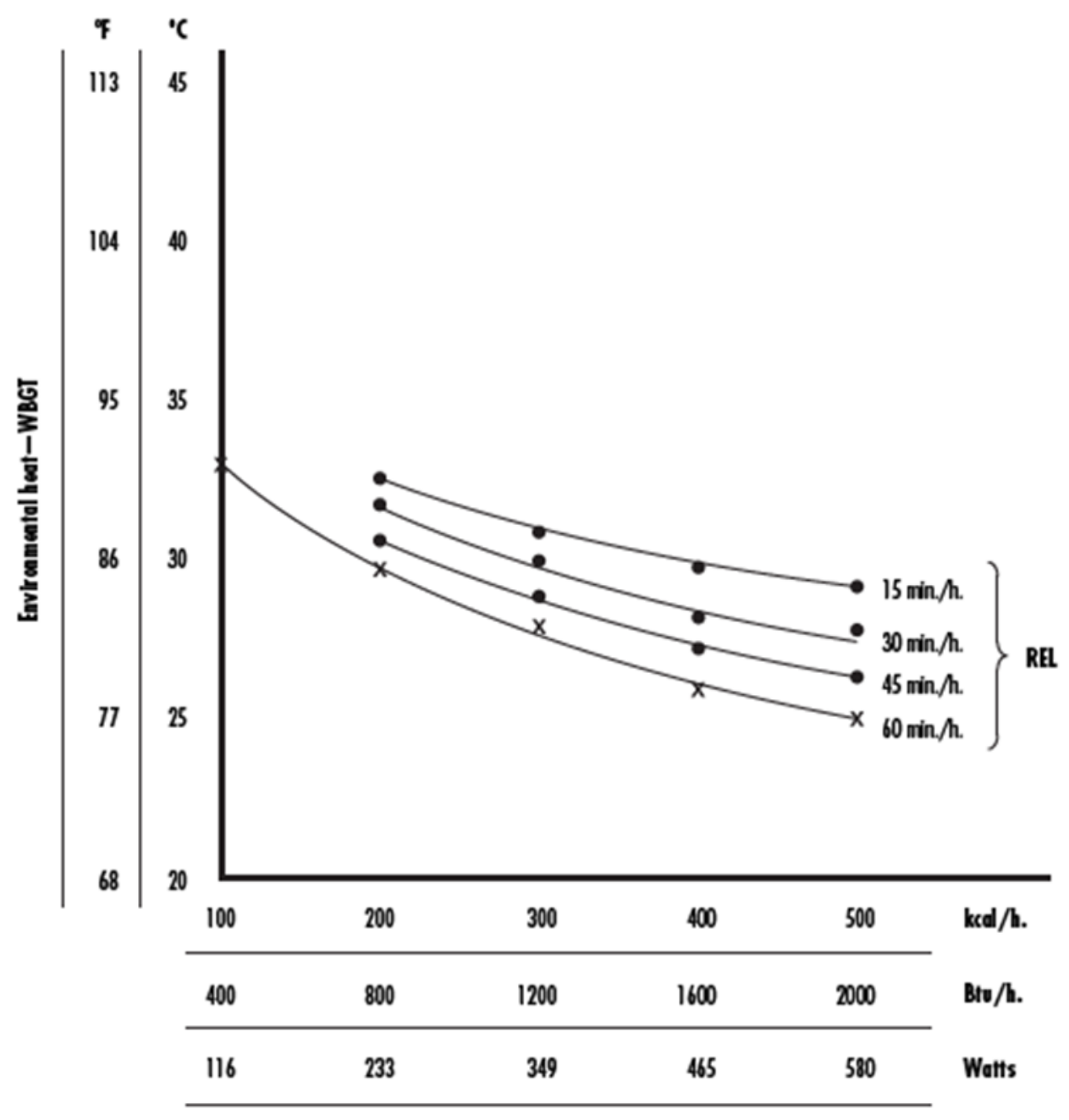

Metabolic heat

Figure B1. NIOSH Recommended heat stress exposure limits (REL) for acclimatized workers [NIOSH 2016]

Even firefighters in optimal physical condition are at continual risk of HRI and rhabdomyolysis from the unavoidable job hazards and risk factors of prolonged exertion and heat exposure. Firefighters are exposed to heat from several sources, including radiant heat from an active fire, ambient temperature, and heat generated by muscles during physical exertion. Physical exertion, and the metabolic heat it generates, is further increased by carrying extra weight of personal protective equipment (PPE), SCBA 
gear, tools, and victims during rescue. PPE may also trap heat, reducing the body's ability to dissipate heat. When a fire department is in a warm and humid climate, the impact of the environment on the health of the firefighter during training and active fire suppression is even more pronounced. Basic heat stress prevention strategies, such as adjusting training activities for outdoor heat conditions and always adhering to the buddy system, should be consistently implemented.

We identified multiple gaps in the facility's heat stress management policy, including insufficient HRI and rhabdomyolysis instruction, absence of instruction to incoming cadets on acclimatization maintenance immediately preceding the start of training, and a lack of guidelines for assessing outdoor weather conditions. Prevention strategies for HRI and rhabdomyolysis should start with providing cadets and instructors with a solid understanding of these medical conditions. The knowledge assessment showed that few participants knew that heat stroke involves a change in mental status. Firefighters should realize the urgent need for immediate action if a colleague isn't "acting right" when in a hot environment or engaging in activities that could raise their core body temperature. Nevertheless, most participants correctly identified work practices that could reduce the risk of heat stroke.

While all participants successfully identified the basic tenets of rhabdomyolysis, there was some confusion about its signs, symptoms, and risk factors. Because most participants listed this department's training materials as their primary source of heat stroke and rhabdomyolysis information, the department can play an instrumental role in cadets' understanding of rhabdomyolysis signs and symptoms. For example, some cadets and instructors were not aware that rhabdomyolysis can occur in the absence of signs and symptoms. This concept is important to help firefighters understand that a prompt medical evaluation is needed once signs and symptoms appear. The rhabdomyolysis injury process could be well underway by the time the affected person feels anything is wrong.

The knowledge assessment revealed that the department's rhabdomyolysis training materials could be further improved by reinforcing the need for serial CK levels to diagnose rhabdomyolysis and follow its progression. A single CK test is insufficient because it doesn't show the healthcare provider if the CK levels are rising or falling. Firefighters should know to ask for serial CK levels to be done if the healthcare provider evaluating them for possible rhabdomyolysis does not include that test in their assessment plan. Some healthcare providers may not be aware of the increased risk of rhabdomyolysis inherent in firefighting or may not obtain an occupational history to assess the often nonspecific symptoms of rhabdomyolysis, etc. The department should also increase cadets' and instructors' knowledge of important rhabdomyolysis risk factors that were not frequently cited in their training materials, such as the importance of maintaining heat acclimatization and the risk of alcohol use in developing rhabdomyolysis.

NIOSH has downloadable wallet cards on the Firefighter Resources webpage for both structural and wildland firefighters to present to healthcare providers informing them of firefighters' occupationally related increased risk for rhabdomyolysis. The wallet card requests that the healthcare provider checks a CK level in firefighters presenting with possible rhabdomyolysis-related symptoms. The webpage also has a fact sheet for healthcare providers that firefighters may use to increase communication on these issues with their healthcare providers. Starting new medications (prescription or over the counter), 
developing new medical conditions, or obtaining seasonal influenza vaccinations are opportunities for firefighters and their healthcare providers to take inventory of all the firefighters' current rhabdomyolysis risk factors and possible approaches to reduce those risks.

The unofficial policy that allows the start of the training day to be moved back 1 hour at the course instructor's discretion demonstrates the type of scheduling flexibility needed during the summer months when a cadet can easily exceed the REL. Expanding this scheduling flexibility to accommodate outdoor heat conditions, especially when strenuous physical activity or when live fire exercises are occurring, is an important next step to improving the overall heat stress management policy. To determine when the training schedule should be adjusted, the training facility will need to determine how they will measure outdoor heat conditions. Because the training facility is near a major municipal airport, the airport weather data could be used to calculate heat index or approximate the WBGT, which requires a separate instrument to measure.

Although we did not assess potential barriers to seeking care for possible HRI and rhabdomyolysis symptoms in this evaluation, these issues were identified in a previous Health Hazard Evaluation report concerning HRI and rhabdomyolysis in structural firefighter cadets during their training program [NIOSH 2015]. Cadets' concern about out-of-pocket expenses for medical evaluation and treatment, along with concern about not being able to return to the training program or work, were identified as potential barriers to symptom reporting. Those concerns were addressed by that department's workers' compensation office representative by documenting the work-relatedness of this "injury" at the time of the initial medical evaluation and by the department's leadership by providing a clearly stated return-towork/training policy following medical clearance [NIOSH 2015].

This department has been proactive in ensuring cadets understand the workers' compensation injury and incident reporting process by reviewing this material in the first week of each training course. Including a statement on the department's return-to-work policy during the training course may provide additional reassurance that a cadet or incumbent would be allowed to return to work once medically cleared following an event of HRI/rhabdomyolysis. 


\section{Limitations}

We only observed cadets training outdoors and assessed the environmental conditions during limited periods on the two days of our visit. Observed activities may not be representative of other activities cadets perform on other training days. Additionally, we did not assess cadets conducting exercises wearing full turnout gear and/or SCBAs or during a live fire exercise. The small size and homogenous nature of the cadet class, along with few sampling opportunities during outdoor physical exercises, limit the generalizability of our evaluation results. The results of our knowledge assessment may be an overestimate of the knowledge base of cadets and instructors in general as the events of the first day of training may have resulted in an increased awareness of HRI and rhabdomyolysis among the cadets and instructors of this class. Because of the small number of instructors (certified firefighters versus cadets in training) participating in this evaluation, we were also unable to ascertain the source of the disparity between the number of HRI/rhabdomyolysis cases reported by cadets and the number of HRI/rhabdomyolysis cases reported by incumbent firefighters.

\section{Conclusions}

High exertion levels and elevated core body temperatures, inherent components of firefighter cadet training programs, represent potential risk factors for HRI and rhabdomyolysis among participants. Several factors at this training center may contribute to an increased risk of HRI and rhabdomyolysis among cadets. These include outdoor environmental conditions, gaps in knowledge about HRI and rhabdomyolysis, and the absence of basic HRI prevention measures. Our review identified multiple areas of improvement for the department's heat stress management program and HRI and rhabdomyolysis training materials. 


\section{Section C: Tables}

Table C1. Results of knowledge assessment*

\begin{tabular}{|c|c|c|c|}
\hline \multirow[t]{2}{*}{ Knowledge statement } & \multicolumn{3}{|c|}{ No. (\%) answering correctly } \\
\hline & $\begin{array}{c}\text { All } \\
\text { participants } \\
(\mathrm{n}=47)\end{array}$ & $\begin{array}{c}\text { Instructors } \\
\text { only } \\
(n=7)\end{array}$ & $\begin{array}{l}\text { Cadets only } \\
(n=40)\end{array}$ \\
\hline Q4. True/False statements about heat stroke (all 4 correct) & $7(15 \%)$ & $1(14 \%)$ & $6(15 \%)$ \\
\hline $\begin{array}{l}\text { Heat stroke can be fatal if not recognized and treated } \\
\text { quickly (true) }\end{array}$ & $46(98 \%)$ & $7(100 \%)$ & $39(98 \%)$ \\
\hline $\begin{array}{l}\text { The buddy system does not help in early recognition of } \\
\text { heat stroke (false) }\end{array}$ & $45(96 \%)$ & $6(86 \%)$ & $39(98 \%)$ \\
\hline $\begin{array}{l}\text { The core body temperature has to be above } 102^{\circ} \mathrm{F} \text { to be } \\
\text { heat stroke (false) }\end{array}$ & $40(85 \%)$ & $6(86 \%)$ & $34(85 \%)$ \\
\hline $\begin{array}{l}\text { Heat stroke is a change in mental status while in a hot } \\
\text { environment (true) }\end{array}$ & $14(30 \%)$ & $2(29 \%)$ & $12(30 \%)$ \\
\hline $\begin{array}{l}\text { Q5. True/False statements about work practices that may } \\
\text { reduce the risk of heat stroke (all } 6 \text { correct) }\end{array}$ & $37(79 \%)$ & $7(100 \%)$ & $30(75 \%)$ \\
\hline Easy access to hydration fluids and cooling areas (true) & $47(100 \%)$ & $7(100 \%)$ & $40(100 \%)$ \\
\hline Taking medications that suppress the heart rate (false) & $47(100 \%)$ & $7(100 \%)$ & $40(100 \%)$ \\
\hline Wearing turnout gear (false) & $47(100 \%)$ & $7(100 \%)$ & $40(100 \%)$ \\
\hline None of the above (false) & $47(100 \%)$ & $7(100 \%)$ & $40(100 \%)$ \\
\hline Work/rest cycles (true) & $46(98 \%)$ & $7(100 \%)$ & $39(98 \%)$ \\
\hline $\begin{array}{l}\text { Following an acclimatization program on return from leave } \\
\text { (true) }\end{array}$ & $37(79 \%)$ & $7(100 \%)$ & $30(75 \%)$ \\
\hline $\begin{array}{l}\text { Q6. True/False statements about rhabdomyolysis } \\
\text { (all } 5 \text { correct) }\end{array}$ & $47(100 \%)$ & $7(100 \%)$ & $40(100 \%)$ \\
\hline Rhabdomyolysis is the breakdown of muscle tissue (true) & $47(100 \%)$ & $7(100 \%)$ & $40(100 \%)$ \\
\hline Rhabdomyolysis is never fatal (false) & $47(100 \%)$ & $7(100 \%)$ & $40(100 \%)$ \\
\hline $\begin{array}{l}\text { Getting rhabdomyolysis is a sure sign you're not in good } \\
\text { physical condition (false) }\end{array}$ & $47(100 \%)$ & $7(100 \%)$ & $40(100 \%)$ \\
\hline $\begin{array}{l}\text { Only people who don't have a healthy diet get } \\
\text { rhabdomyolysis (false) }\end{array}$ & $47(100 \%)$ & $7(100 \%)$ & $40(100 \%)$ \\
\hline $\begin{array}{l}\text { Rhabdomyolysis can be diagnosed just by physical exam } \\
\text { findings (false) }\end{array}$ & $47(100 \%)$ & $7(100 \%)$ & $40(100 \%)$ \\
\hline
\end{tabular}

* Question 1 asked participants to self-identify as either instructor vs cadet; Question 2 asked participants' age; and Question 3 asked participants if they had any prior firefighting experience (wildland or structural). 
Table C1 continued. Results of knowledge assessment*

\begin{tabular}{|c|c|c|c|}
\hline \multirow[t]{2}{*}{ Knowledge statement } & \multicolumn{3}{|c|}{ No. (\%) answering correctly } \\
\hline & $\begin{array}{c}\text { All } \\
\text { participants } \\
(\mathrm{n}=47)\end{array}$ & $\begin{array}{c}\text { Instructors } \\
\text { only } \\
(n=7)\end{array}$ & $\begin{array}{l}\text { Cadets only } \\
(\mathrm{n}=40)\end{array}$ \\
\hline $\begin{array}{l}\text { Q7. True/False statements about signs and symptoms } \\
\text { associated with rhabdomyolysis (all } 10 \text { correct) }\end{array}$ & $1(2 \%)$ & $0(0 \%)$ & $1(3 \%)$ \\
\hline No visible signs or symptoms (true) & $21(45 \%)$ & $4(57 \%)$ & $17(43 \%)$ \\
\hline Severe muscle pain (true) & $47(100 \%)$ & $7(100 \%)$ & $40(100 \%)$ \\
\hline Exercise intolerance (true) & $42(89 \%)$ & $7(100 \%)$ & $35(88 \%)$ \\
\hline Tea- or cola-colored urine (true) & $44(94 \%)$ & $7(100 \%)$ & $37(93 \%)$ \\
\hline Kidney failure (true) & $47(100 \%)$ & $7(100 \%)$ & $40(100 \%)$ \\
\hline Cardiac arrhythmias (true) & $38(81 \%)$ & $7(100 \%)$ & $31(78 \%)$ \\
\hline Seizures (true) & $38(81 \%)$ & $7(100 \%)$ & $31(78 \%)$ \\
\hline Permanent disability (true) & $40(85 \%)$ & $7(100 \%)$ & $33(83 \%)$ \\
\hline Heat rash (false) & $11(23 \%)$ & $3(43 \%)$ & $8(20 \%)$ \\
\hline Pain on urination (false) & $5(11 \%)$ & $0(0 \%)$ & $5(13 \%)$ \\
\hline \multicolumn{4}{|c|}{ Q9*. Write-in answers to "Name as many rhabdomyolysis risk factors as you can" } \\
\hline No risk factors listed & $4(9 \%)$ & $1(14 \%)$ & $3(8 \%)$ \\
\hline \multicolumn{4}{|l|}{ Correctly identified rhabdomyolysis risk factors by category } \\
\hline $\begin{array}{l}\text { Overexertion (exercise, conditioning, marathon running, } \\
\text { sports, job tasks, or work) }\end{array}$ & $32(68 \%)$ & $5(57 \%)$ & $27(68 \%)$ \\
\hline $\begin{array}{l}\text { Use of stimulants (caffeine, energy drinks, } \\
\text { thermogenic/pre-workout supplements, etc.) }\end{array}$ & $23(49 \%)$ & $4(57 \%)$ & $19(48 \%)$ \\
\hline $\begin{array}{l}\text { Hyperthermia (increased body temperature, heat } \\
\text { exposure, or hot weather) }\end{array}$ & $21(45 \%)$ & $3(43 \%)$ & $18(45 \%)$ \\
\hline $\begin{array}{l}\text { Medical conditions associated with rhabdomyolysis (sickle } \\
\text { cell disease, etc.) }\end{array}$ & $16(34 \%)$ & $5(71 \%)$ & $11(28 \%)$ \\
\hline $\begin{array}{l}\text { Medications associated with rhabdomyolysis (statins, high } \\
\text { blood pressure/heart medications, etc.) }\end{array}$ & $7(15 \%)$ & $3(43 \%)$ & $4(10 \%)$ \\
\hline No heat acclimatization & $3(6 \%)$ & $1(14 \%)$ & $2(5 \%)$ \\
\hline Use of alcohol & $1(2 \%)$ & $1(14 \%)$ & $0(0 \%)$ \\
\hline $\begin{array}{l}\text { Incorrectly identified risk factors for rhabdomyolysis } \\
\text { (responses included: dehydration, insufficient sleep, poor } \\
\text { diet, etc.) }\end{array}$ & $39(83 \%)$ & $5(71 \%)$ & $34(85 \%)$ \\
\hline \multicolumn{4}{|c|}{ Q10. Write-in answers to "Where do you get information about heat stroke and rhabdomyolysis?" } \\
\hline Department training materials & $26(55 \%)$ & $5(71 \%)$ & $21(53 \%)$ \\
\hline Online resources (i.e., WebMD) & $19(40 \%)$ & $4(57 \%)$ & $15(38 \%)$ \\
\hline Coworkers/friends & $14(30 \%)$ & $2(29 \%)$ & $12(30 \%)$ \\
\hline Other & $10(21 \%)$ & $0(0 \%)$ & $10(25 \%)$ \\
\hline Own healthcare provider & $3(6 \%)$ & $1(14 \%)$ & $2(5 \%)$ \\
\hline $\begin{array}{l}\text { I have not received or looked up any information on heat } \\
\text { stroke and/or rhabdomyolysis }\end{array}$ & $6(13 \%)$ & $1(14 \%)$ & $5(13 \%)$ \\
\hline
\end{tabular}

* Question 8 asked participants to identify the correct laboratory test used to diagnose rhabdomyolysis. 
Table C2. Historical weather conditions on the day of the incident in June 2018 from Weather Underground

\begin{tabular}{lcccccc}
\hline Local time & $\begin{array}{c}\text { Air temperature } \\
\left({ }^{\circ} \mathrm{F}\right)\end{array}$ & $\begin{array}{c}\text { Dew point } \\
\left({ }^{\circ} \mathrm{F}\right)\end{array}$ & $\begin{array}{c}\text { Relative } \\
\text { humidity }\end{array}$ & $\begin{array}{c}\text { Wind } \\
\text { direction }\end{array}$ & $\begin{array}{c}\text { Wind speed } \\
\text { (miles per hour) }\end{array}$ & $\begin{array}{c}\text { Cloud } \\
\text { conditions }\end{array}$ \\
\hline 6:53 a.m. & 90 & 71 & $54 \%$ & South & 13 & Partly Cloudy \\
7:53 a.m. & 94 & 70 & $46 \%$ & $\begin{array}{c}\text { South- } \\
\text { Southeast }\end{array}$ & 15 & Mostly Cloudy \\
\hline
\end{tabular}




\section{Section D: Occupational Exposure Limits}

NIOSH investigators refer to mandatory (legally enforceable) and recommended occupational exposure limits (OELs) for chemical, physical, and biological agents when evaluating workplace hazards. OELs have been developed by federal agencies and safety and health organizations to prevent adverse health effects from workplace exposures. Generally, OELs suggest levels of exposure that most employees may be exposed to for up to 10 hours per day, 40 hours per week, for a working lifetime, without experiencing adverse health effects.

However, not all employees will be protected if their exposures are maintained below these levels. Some may have adverse health effects because of individual susceptibility, a preexisting medical condition, or a hypersensitivity (allergy). In addition, some hazardous substances act in combination with other exposures, with the general environment, or with medications or personal habits of the employee to produce adverse health effects. Most OELs address airborne exposures, but some substances can be absorbed directly through the skin and mucous membranes.

Most OELs are expressed as a time-weighted average (TWA) exposure. A TWA refers to the average exposure during a normal 8- to 10-hour workday. Some chemical substances and physical agents have recommended short-term exposure limits (STEL) or ceiling values. Unless otherwise noted, the STEL is a 15-minute TWA exposure. It should not be exceeded at any time during a workday. The ceiling limit should not be exceeded at any time.

In the United States, OELs have been established by federal agencies, professional organizations, state and local governments, and other entities. Some OELs are legally enforceable limits; others are recommendations.

- The Occupational Safety and Health Administration (OSHA), an agency of the U.S. Department of Labor, publishes permissible exposure limits [29 CFR 1910 for general industry; 29 CFR 1926 for construction industry; and 29 CFR 1917 for maritime industry] called PELs. These legal limits are enforceable in workplaces covered under the Occupational Safety and Health Act of 1970.

- NIOSH RELs are recommendations based on a critical review of the scientific and technical information and the adequacy of methods to identify and control the hazard. NIOSH RELs are published in the NIOSH Pocket Guide to Chemical Hazards [NIOSH 2007]. NIOSH also recommends risk management practices (e.g., engineering controls, safe work practices, employee education/training, PPE, and exposure and medical monitoring) to minimize the risk of exposure and adverse health effects.

- Another set of OELs commonly used and cited in the United States include the threshold limit values or TLVs, which are recommended by ACGIH. The ACGIH TLVs are developed by committee members of this professional organization from a review of the published, peerreviewed literature. TLVs are not consensus standards. They are considered voluntary exposure guidelines for use by industrial hygienists and others trained in this discipline "to assist in the control of health hazards" [ACGIH 2019]. 
Outside the United States, OELs have been established by various agencies and organizations and include legal and recommended limits. The Institut für Arbeitsschutz der Deutschen Gesetzlichen Unfallversicherung (Institute for Occupational Safety and Health of the German Social Accident Insurance) maintains a database of international OELs from European Union member states, Canada (Québec), Japan, Switzerland, and the United States. The database, available at https://www.dguv.de/ifa/gestis/gestis-stoffdatenbank/index-2.jsp, contains international limits for more than 2,000 hazardous substances and is updated periodically.

OSHA (Public Law 91-596) requires an employer to furnish employees a place of employment free from recognized hazards that cause or are likely to cause death or serious physical harm. This is true in the absence of a specific OEL. It also is important to keep in mind that OELs may not reflect current health-based information.

When multiple OELs exist for a substance or agent, NIOSH investigators generally encourage employers to use the lowest OEL when making risk assessment and risk management decisions.

\section{Heat Stress}

Many heat stress guidelines have been developed to protect people against HRIs. The objective of any heat stress index is to prevent a person's core body temperature (CBT) from rising excessively. In 1969, the World Health Organization published a document that concluded, "it is inadvisable for CBT to exceed $100.4^{\circ} \mathrm{F}$ or for oral temperature to exceed $99.5^{\circ} \mathrm{F}$ in prolonged daily exposure to heavy work and/or heat" [World Health Organization 1969]. Additionally, a CBT of $102.2^{\circ} \mathrm{F}$ should be considered reason to terminate exposure even when CBT is being monitored [NIOSH 2016]. This does not mean that an employee with a CBT exceeding those levels will necessarily experience adverse health effects. However, the number of unsafe acts increases as does the risk of developing heat stress illnesses [NIOSH 2016].

NIOSH recommends controlling total heat exposure so that unprotected healthy employees are not exposed to metabolic and environmental heat combinations that exceed the applicable NIOSH criteria. These criteria state that most healthy employees who work in hot environments and are exposed to combinations of environmental and metabolic heat below the NIOSH RAL for unacclimatized employees or the NIOSH REL for acclimatized employees should be protected from adverse health effects [NIOSH 2016]. Additional modifications (e.g., employee health interventions, clothing, and PPE) may be needed to protect employees from heat stress.

The recently updated NIOSH Criteria for a Recommended Standard on Occupational Exposure to Heat and Hot Environments is available at https://www.cdc.gov/niosh/docs/2016-106/pdfs/2016106.pdf. The criteria include a checklist of basic preventive practices that should be followed to control heat stress among employees working in hot environments:

- Reduce physical demands of the work and use powered assistance for heavy tasks.

- Increase exposure time in hot environmental conditions gradually over 7-14 days.

- Shorten duration of each exposure.

- Modify schedules so hot jobs occur during cooler parts of the day. 
- Encourage water intake at frequent intervals to prevent dehydration.

- Train employees in safety and health procedures for work in hot environments.

- Provide initial and periodic medical examinations to determine whether an employee can meet the total demands and physical stresses of the job with reasonable assurances the health and safety of the employee and/or fellow employees will not be placed at risk [NIOSH 2016].

The ACGIH heat stress guidelines use a decision-making process that provides step-by-step situationdependent instructions that factor in clothing insulation values and physiological evaluation of heat strain [ACGIH 2019]. ACGIH WBGT screening criteria factor in the ability of the body to cool itself (clothing insulation value, humidity, and wind) and, like the NIOSH criteria, can be used to develop work/rest regimens for acclimatized and unacclimatized employees. The ACGIH WBGT-based heat exposure assessment was developed for a traditional work uniform of long-sleeved shirt and pants, and represents conditions under which it is believed that nearly all adequately hydrated, unmedicated, healthy employees may be repeatedly exposed without adverse health effects. Clothing insulation values and the appropriate WBGT adjustments, as well as descriptors of the other decision-making process components can be found in the ACGIH document Documentation of the Threshold Limit Values for Chemical Substances and Physical Agents and Biological Exposure Indices [ACGIH 2001]. The ACGIH TLV for heat stress provides a framework for the control of HRIs only. Although accidents and injuries can increase with increasing levels of heat stress, it is important to note that the TLVs are not directed toward controlling these outcomes [ACGIH 2019].

NIOSH and ACGIH criteria can only be used when WBGT data for the immediate work area are available and must not be used when employees wear encapsulating suits or garments that are impermeable or highly resistant to water vapor or air movement. Further assumptions regarding work demands include an 8-hour workday, 5-day workweek, two 15-minute breaks, and a 30-minute lunch break, with rest area temperatures the same as, or less than, those in work areas, and at least some air movement. While NIOSH and ACGIH guidelines distinguish between safe and dangerous levels, professional judgment must be used in administering a heat stress management program to ensure adequate protection. OSHA does not have an exposure limit for heat stress. However, the OSHA technical manual's section on heat stress refers to the ACGIH document for guidelines to evaluate employee heat stress and how to investigate the workplace [OSHA 2017].

\section{Heat Strain}

The body's response to heat stress is called heat strain. Operations involving high air temperatures, radiant heat sources, high humidity, direct physical contact with hot objects, and strenuous physical activities have a high potential for inducing heat strain in employees. Heat strain is highly individual and cannot be predicted based on environmental heat stress measurements alone. Physiological monitoring for heat strain becomes necessary when impermeable clothing is worn, when heat stress screening criteria are exceeded, or when data from a detailed analysis such as the International Standards Organization required sweat rate index show excess heat stress.

ACGIH considers one indicator of physiological strain, a sustained, elevated peak heart rate, to be a useful measure of acute exposure to high-level heat stress. Sustained peak heart rate, defined by ACGIH 
as 180 beats per minute (bpm) minus an individual's age over several minutes, is a leading indicator that thermal regulatory control may not be adequate and that increases in CBTs have occurred or will soon occur [ACGIH 2019]. According to ACGIH, an individual's heat stress exposure should be discontinued when any of the following heat strain indicators occur:

- Sustained (over several minutes) heart rate exceeds $180 \mathrm{bpm}$ minus the individual's age in years for those with normal cardiac performance.

- $\mathrm{CBT}$ is greater than $100.4^{\circ} \mathrm{F}$ for unselected, unacclimatized personnel and greater than $101.3^{\circ} \mathrm{F}$ for medically fit, heat-acclimatized personnel.

- Recovery heart rate at 1 minute after a peak work effort exceeds $110 \mathrm{bpm}$.

- Presence of symptoms of sudden and severe fatigue, nausea, dizziness, and lightheadedness.

In addition, ACGIH states than an individual may be at greater risk of heat strain if these indicators are present:

- Profuse sweating is sustained over several hours.

- Weight loss over a shift is greater than $1.5 \%$ of body weight.

Twenty-four-hour urinary sodium excretion is less than 55 millimoles.

\section{Acclimatization}

When employees are first exposed to a hot environment, they may show signs of distress and discomfort, experience increased CBTs and heart rates, and may have headache or nausea. However, following repeated exposure, employees can adapt to the hot environment. This adaptation is called acclimatization. A well-designed heat-acclimatization program will decrease the risk for HRI. Heat acclimatization usually occurs after 7-14 days of exposure to a hot environment. For new employees, an acclimatization program should schedule no more than $20 \%$ of the duration of work in the hot environment on Day 1 and increase the duration by no more than $20 \%$ on each additional day [NIOSH 2016].

Employees begin to lose acclimatization when they stop working in the heat stress conditions, and a noticeable loss occurs after 4 days. However, this loss is usually rapidly made up. Chronic illness, a short episode of mild illness (e.g., gastroenteritis), the use or misuse of pharmacologic agents, a sleep deficit, poor nutrition, or a disturbed water and electrolyte balance may reduce an employee's capacity to acclimatize [ACGIH 2019]. For employees who have had previous experience working in hot environmental conditions, the acclimatization program should schedule no more than $50 \%$ of the duration of work in the hot environment on Day 1, 60\% on Day 2, 80\% on Day 3, and 100\% on Day 4 [NIOSH 2016].

\section{Rhabdomyolysis}

Rhabdomyolysis is a medical condition associated with heat stress and prolonged physical exertion, resulting in the rapid breakdown of muscle that can damage the kidneys. Classic symptoms of rhabdomyolysis are muscle pain, cramping, swelling, weakness, and decreased range-of-motion of joints. 
One of the signs of rhabdomyolysis is tea- or cola-colored urine [Brudvig and Fitzgerald 2007; Cervellin et al. 2010; Khan 2009]. However, symptoms vary between individuals, and some might not have any symptoms at all [Brudvig and Fitzgerald 2007; Huerta-Alardin et al. 2004].

Rhabdomyolysis is diagnosed by serial measurement of CK, also known as creatine kinase or creatine phosphokinase (CPK), in the blood by a licensed healthcare provider. The severity of rhabdomyolysis depends upon damage to other organ systems and the peak CK level. Mild rhabdomyolysis can be treated by drinking lots of fluids [George et al. 2010]. Severe cases require hospitalization to provide fluids intravenously, monitor CK levels to guide treatment, and follow kidney function as emergent dialysis may be needed if the kidneys fail. [Bosch et al. 2009]. Inpatient monitoring would also include cardiac telemetry to look for abnormal heart rhythms induced by high potassium levels, neurological monitoring for seizures, and neurovascular monitoring for compartment syndrome.

It is not uncommon for individuals who engage in exertional activities higher than their baseline level of fitness to develop exertional rhabdomyolysis. However, it also occurs in highly conditioned individuals who may engage in supramaximal exercise (extreme short duration anaerobic exercise) or who have other risk factors along with an exertional activity [Walsh and Page 2006]. 


\section{Section E: Heat Stroke and Rhabdomyolysis Knowledge Assessment}

Please answer the questions below as completely as you can. Thank you!

1) Are you currently a $\square$ cadet or $\square$ instructor? (Please check one)

2) What is your age? ___ years

3) Prior to the start of this cadet course, have you had any prior experience as a structural or wildland firefighter (paid or volunteer)? $\square$ Yes $\square$ No

4) Which of the following is/are true statement(s) about heat stroke?
a. $\square$ The core body temperature has to be above $102^{\circ} \mathrm{F}$ to be heat stroke.
b. $\square$ Heat stroke is a change in mental status while in a hot environment.
c. $\square$ The buddy system does not help in early recognition of heat stroke.
d. $\square$ Heat stroke can be fatal if not recognized and treated quickly.

5) Which of the following work practices may reduce the risk of heat stroke? (check all that apply)
a. $\square$ Following an acclimatization program on return from leave
d. $\square$ Wearing turnout gear
b. $\square$ Taking medications that suppress the heart rate
e. $\square$ Work/rest cycles
c. $\square$ Easy access to hydration fluids and cooling areas
f. $\square$ None of the above

6) Check the true statement below
a. $\square$ Rhabdomyolysis is never fatal.
b. $\square$ Getting rhabdomyolysis is a sure sign you're not in good physical condition
c. $\square$ Only people who don't have a healthy diet get rhabdomyolysis
d. $\square$ Rhabdomyolysis is the breakdown of muscle tissue.
e. $\square$ Rhabdomyolysis can be diagnosed just by physical exam findings.

7) Which of the following are NOT associated with rhabdomyolysis? (Check all that apply)
a. $\square$ Cardiac arrhythmias
f. $\square$ Severe muscle pain
b. $\square$ Seizures
g. $\square$ Pain on urination
c. $\square$ Kidney failure
h. $\square$ Exercise intolerance (can't complete routine workout)
d. $\square$ Heat rash
i. $\square$ Tea or cola colored urine
e. $\square$ Permanent disability
j. $\square$ No visible signs or symptoms 
8) What laboratory test is needed to make a definitive diagnosis of rhabdomyolysis? (Check one)
a. $\square$ Troponin
c. $\square$ Creatine kinase $(\mathrm{CK})$ or Creatine phosphokinase (CPK)
b. $\square$ Urinary myoglobin
d. $\square$ Acetocholinesterase

9) Name as many rhabdomyolysis risk factors (i.e. medications, supplements, medical conditions, injuries, tasks, etc. that are associated with the development of rhabdomyolysis) as you can:

10) Where did you get information about heat stroke and rhabdomyolysis? (Check all that apply)

$\square$ Fire Department training materials $\quad \square$ Your healthcare provider

Online resources (i.e., WebMD) $\square$ Coworkers/friends

Other (please specify:

$\square$ Not applicable (I have not received or looked up any information about heat stroke and rhabdomyolysis)

END OF SURVEY - THANK YOU FOR PARTICIPATING

Answers

1-3) participant descriptors

4) b and d

5) a, c, and e

6) $d$

7) d and g

8) c

9) Crush injury, hyperthermia, thermal/electrical burn, overexertion or muscle overuse (e.g., high intensity physical fitness programs, marathon running, grand mal seizures, etc.), OTC meds (e.g., diphenhydramine, phenylephrine, etc.), Rx meds (e.g., statins, tricyclic antidepressants, cyclosporine, corticosteroids, erythromycin, colchicine, etc.), illicit drugs (e.g., cocaine, methamphetamine [causes direct vasoconstriction], and heroin [causes one to lay in same position for extended periods]), supplements (e.g., caffeine, ephedra, kava kava, etc.), inborn errors of metabolism, sickle cell disease, viral infections (e.g., Influenza A and B, Epstein-Barr, HIV, etc.), bacterial infections (e.g., salmonella, legionella, staph, strep, etc.). 


\section{Section F: References}

\section{Heat-related IIIness and Rhabdomyolysis}

Bosch X, Poch E, Grau JM [2009]. Rhabdomyolysis and acute kidney injury. N Engl J Med 361:62-72, http://dx.doi.org/10.1056/NEJMra0801327.

Brudvig TJ, Fitzgerald PI [2007]. Identification of signs and symptoms of acute exertional rhabdomyolysis in athletes: a guide for the practitioner. Strength Cond J 29(1):10-14, http://dx.doi.org/10.1519/00126548-200702000-00001.

Centers for Disease Control and Prevention [1990]. Exertional rhabdomyolysis and acute renal impairment-New York City and Massachusetts, 1988. MMWR 39(42):751-756, https://www.cdc.gov/mmwr/preview/mmwrhtml/00001812.htm.

Cervellin G, Comelli I, Lippi G [2010]. Rhabdomyolysis: historical background, clinical, diagnostic and therapeutic features. Clin Chem Lab Med 48(6):749-756, http://dx.doi.org/10.1515/CCLM.2010.151.

Fahy RF [2005]. U.S. firefighter fatalities due to sudden cardiac death, 1995-2004. Fire Analysis and Research Division, National Fire Protection Association, June 2005, http://tkolb.net/FireReports/2012/FF CardiacDeath95-04.pdf.

George M, Delgaudio A, Salhanick SD [2010]. Exertional rhabdomyolysis-when should we start worrying?: case reports and literature review. Pediatr Emerg Care 26(11):864-866, http://dx.doi.org/10.1097/PEC.0b013e3181f9dcd1.

Huerta-Alardin AL, Varon J, Marik PE [2004]. Bench-to-bedside review: rhabdomyolysis - an overview for clinicians. Crit Care 9(2):158-229, http://dx.doi.org/10.1186/cc2978.

Khan FY [2009]. Rhabdomyolysis: a review of the literature. Neth J Med 67(9):272-283.

Kunadharaju K, Smith TD, DeJoy DM [2011]. Line-of-duty deaths among U.S. firefighters: an analysis of fatality investigations. Accid Anal Prev 43(3):1171-1180, https://doi.org/10.1016/j.aap.2010.12.030.

NFPA [2018]. Standard on comprehensive occupational medical program for fire departments. NFPA 1582. Quincy, MA: National Fire Protection Association,

http://mtfd22.com/download/50/sogs/5308/501a-physicals-nfpa-1582-2018-standard.pdf.

NIOSH [2015]. Evaluation of heat stress, heat strain, and rhabdomyolysis during structural firefighter training. By Eisenberg J, Methner M, Dowell CH, Mueller C. Cincinnati, OH: U.S. Department of Health and Human Services, Centers for Disease Control and Prevention, National Institute for Occupational Safety and Health, Health Hazard Evaluation Report 2012-0039-3242, http://www.cdc.gov/niosh/hhe/reports/pdfs/2012-0039-3242.pdf.

NIOSH [2016]. NIOSH criteria for a recommended standard: occupational exposure to heat and hot environments. By Jacklitsch B, Williams WJ, Musolin K, Coca A, Kim J-H, Turner N. Cincinnati, OH: U.S. Department of Health and Human Services, Centers for Disease Control and Prevention, National Institute for Occupational Safety and Health, DHHS (NIOSH) Publication No. 2016-106, https://www.cdc.gov/niosh/docs/2016-106/. 
NIOSH [2018]. Cadet dies from hyperthermia and exertional heat stroke during indoor SCBA maze training-Texas. By Baldwin T. Cincinnati, OH: U.S. Department of Health and Human Services, Centers for Disease Control and Prevention, National Institute for Occupational Safety and Health, F2016-05, https://www.cdc.gov/niosh/fire/pdfs/face201605.pdf.

Walsh JJ, Page SM [2006]. Rhabdomyolysis and compartment syndrome in military trainees. In: DeKoning BL, ed. Recruit Medicine. Washington, DC: Government Printing Office, https://ke.army.mil/bordeninstitute/published volumes/recruit medicine/RM-ch10.pdf.

\section{Occupational Exposure Limits}

ACGIH [2001]. Heat stress. In: Documentation of the threshold limit values for physical agents, 7 th ed. Cincinnati, OH: American Conference of Governmental Industrial Hygienists.

ACGIH [2019]. 2019 TLVs $^{\circledR}$ and BEIs ${ }^{\circledR}$ : threshold limit values for chemical substances and physical agents and biological exposure indices. Cincinnati, OH: American Conference of Governmental Industrial Hygienists.

NIOSH [2007]. NIOSH pocket guide to chemical hazards. Cincinnati, OH: U.S. Department of Health and Human Services, Centers for Disease Control and Prevention, National Institute for Occupational Safety and Health, DHHS (NIOSH) Publication No. 2005-149, http://www.cdc.gov/niosh/npg/.

OSHA [2017]. OSHA technical manual. Section III: chapter 4: heat stress. Washington, DC: U.S. Department of Labor, Occupational Safety and Health Administration, https://www.osha.gov/dts/osta/otm/otm iii/otm iii 4.html.

World Health Organization [1969]. Technical report series 412: health factors involved in working under conditions of heat stress. Geneva, Switzerland: World Health Organization, https://apps.who.int/iris/bitstream/handle/10665/40716/WHO TRS 412.pdf?sequence=1\&isAllow $\underline{\mathrm{ed}=\mathrm{y}}$. 


\section{Delivering on the Nation's promise: \\ Promoting productive workplaces through safety and health research}

Get More Information

Find NIOSH products and get answers to workplace safety and health questions:

1-800-C DC-INFO (1-800-232-4636) | TTY: 1-888-232-6348

CDC/NIOSH INFO: cdc.gov/info | cdc.gov/niosh

Monthly NIOSH eNews: cdc.gov/niosh/eNews 